The difference between this Act and the "Town Planning" Bill brought in by the President of the Local Government Board is that the former gives the Corporation definite powers on definite lines without going to the L.G.B., whereas the latter gives wide general powers to the Local Government Board to frame town-planning schemes where such are likely to be of use, or approve of a town-planning scheme of any local authority where the board are satisfied that there is a prima facie case for making such a scheme. Time may be lost and uncertainty involved, since there are no precedents, nor " model " regulations.

All conditions of purchases, etc., causing difference of opinion between the parties concerned are adjusted under the provisions of the Arbitration Act of $\mathbf{1} 889$.

\section{THE INFANT MORTALITY IN THE MALTESE ISLANDS.}

By A. CRITIEN, M.D., D.P.H., D.T.M., Medical Officer of Health, Malta.

O

$\mathrm{NE}$ of the most striking features in the health statistics of these islands is the excessive infant mortality, of which the average rate for the past twelve years has been 250.89 per I, ooo births.

In a country with little or no employment of female labour and a very small percentage of illegitimacy, where syphilis and alcoholism are fortunately as yet comparatively inactive, the causes of such a waste of lives must be sought outside the range of social influences and evils.

If we glance at the infant death rate, say for the last seven years, calculated for the urban and suburban as distinct from the rural areas, we become aware of a peculiar fact, viz., that the latter are more adverse to infant life than the former, contrary to what is observed in other countries, where infant mortality in the towns is always higher than in the rural districts.

That infant mortality in Malta is in excess of that recorded for other countries may be seen from the following table:-

\begin{tabular}{|c|c|c|c|c|c|c|c|c|}
\hline DEATHS & OF & $\mathrm{CH}$ & DREN & $\begin{array}{l}\text { UND } \\
\text { IRTH }\end{array}$ & $\mathrm{R}$ ONI & E YE & AR TO & 1,000 \\
\hline England & and & & IgOI. & 1902. & I903. & $\mathrm{rgO}_{4}$. & I905. & $\begin{aligned} 19007 . \\
\end{aligned}$ \\
\hline Norway & $\ldots$ & wales & & & 132 & 145 & $\begin{array}{r}128 \\
8 \pi\end{array}$ & 132 \\
\hline Prussia & $\ldots$ & $\cdots$ & 200 & $\begin{array}{r}75 \\
172\end{array}$ & 194 & 185 & $\begin{aligned} 81 \\
108\end{aligned}$ & ? \\
\hline Austria & $\ldots$ & $\ldots$ & 210 & 218 & $2 \mathrm{II}$ & ? & ? & $1 / 7$ \\
\hline France & $\ldots$ & ... & 142 & 135 & I 37 & 144 & 136 & ? \\
\hline Italy & $\ldots$ & $\ldots$ & 165 & 175 & 168 & 164 & 166 & ? \\
\hline Spain & $\cdots$ & $\cdots$ & 186 & 181 & 162 & 173 & I6I & 173 \\
\hline Lalia & $\cdots$ & $\cdots$ & $\begin{array}{l}\text { 1901. } \\
240\end{array}$ & $\begin{array}{l}\text { rQO2-3. } \\
218\end{array}$ & $\begin{array}{l}1903-4 \cdot I \\
236\end{array}$ & $\begin{array}{l}\text { I904.5. } \\
236\end{array}$ & $\begin{array}{l}1905-6 . \\
244\end{array}$ & $\begin{array}{l}\frac{1906-7 .}{26 I} \\
2 \mathrm{I}\end{array}$ \\
\hline
\end{tabular}

The contrast is more striking when the rates for some towns geographically and ethnologically very near to us are compared with ours, as follows :-

Deaths OF ChILDREN UNDER ONE YeAR TO I,OOO BirThS.

$\begin{array}{lllllllll} & & & \text { 190r. } & \text { 1902. } & \text { 1903. } & \text { 1904. } & \text { 1905. } & \text { 1906. } \\ \text { Naples } & \ldots & \ldots & 108 & 149 & 155 & 159 & 159 & - \\ \text { Palernio } & \ldots & \ldots & 125 & 136 & 147 & 132 & & 154 \\ \text { Catania } & \ldots & \ldots & 141 & 159 & 184 & 139 & 189 & - \\ \text { Malta } & \ldots & \ldots & 240 & 218 & 236 & 236 & 244 & 261\end{array}$

In order to study the peculiar incidence of disease in these islands and to compare the same with that of England and Wales, the mortality under one year for the different diseases has been calculated and tabulated as follows. In a separate column the average rates for England and Wales have been given. Common Infectious Diseases.

The first notable fact under this heading is the absence of scarlet fever as a cause of death in Malta. This would not be so remarkable were it true only for the age group under consideration. It may be said at once that, unlike diphtheria, scarlet fever has failed to establish itself in these islands. Cases are imported and sporadic attacks occur every now and then, but although one would expect that closely aggregated communities should afford immense facilities for the dissemination of so highly an infectious disease, scarlet fever has never been known to spread.

Measles occur in epidemics at irregular intervals of from three to six years. Although a notifiable disease, the proportion of cases notified is very small, as medical advice is sought, as a rule, when the attacks are severe or when the life of the patient is in danger through some complication. The extent of an outbreak can, therefore, be gauged only by the number of deaths. During an epidemic and for many months after, deaths from pulmonary diseases show a decided increase. This is observed in a remarkable degree when the epidemic occurs in winter, which is never so cold as to check its spread.

Here, as elsewhere, measles is regarded as a trivial disease. If it once gets into a house, little or no attempts are made to shield the susceptible persons; on the contrary, the peculiar frame of mind prevails that the sooner the children all go through it the better.

Epidemics reach their acme during the winter months and die away towards May or June. In these islands as in other countries, measles is most destructive to infants between one and two years of age; but the first year of life is also considerably affected, no less than 
Deaths of ChILdRen UNDER ONE Year to I,OOO Births,

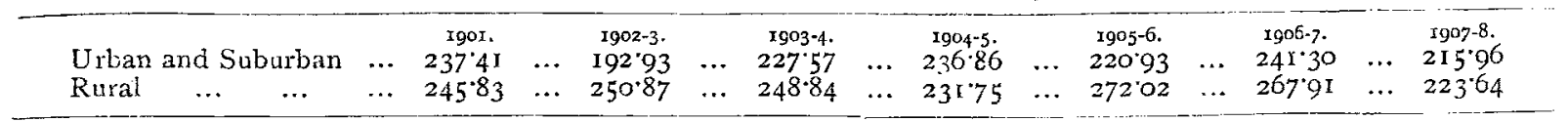

Mortality of Infants-Both SeXes.

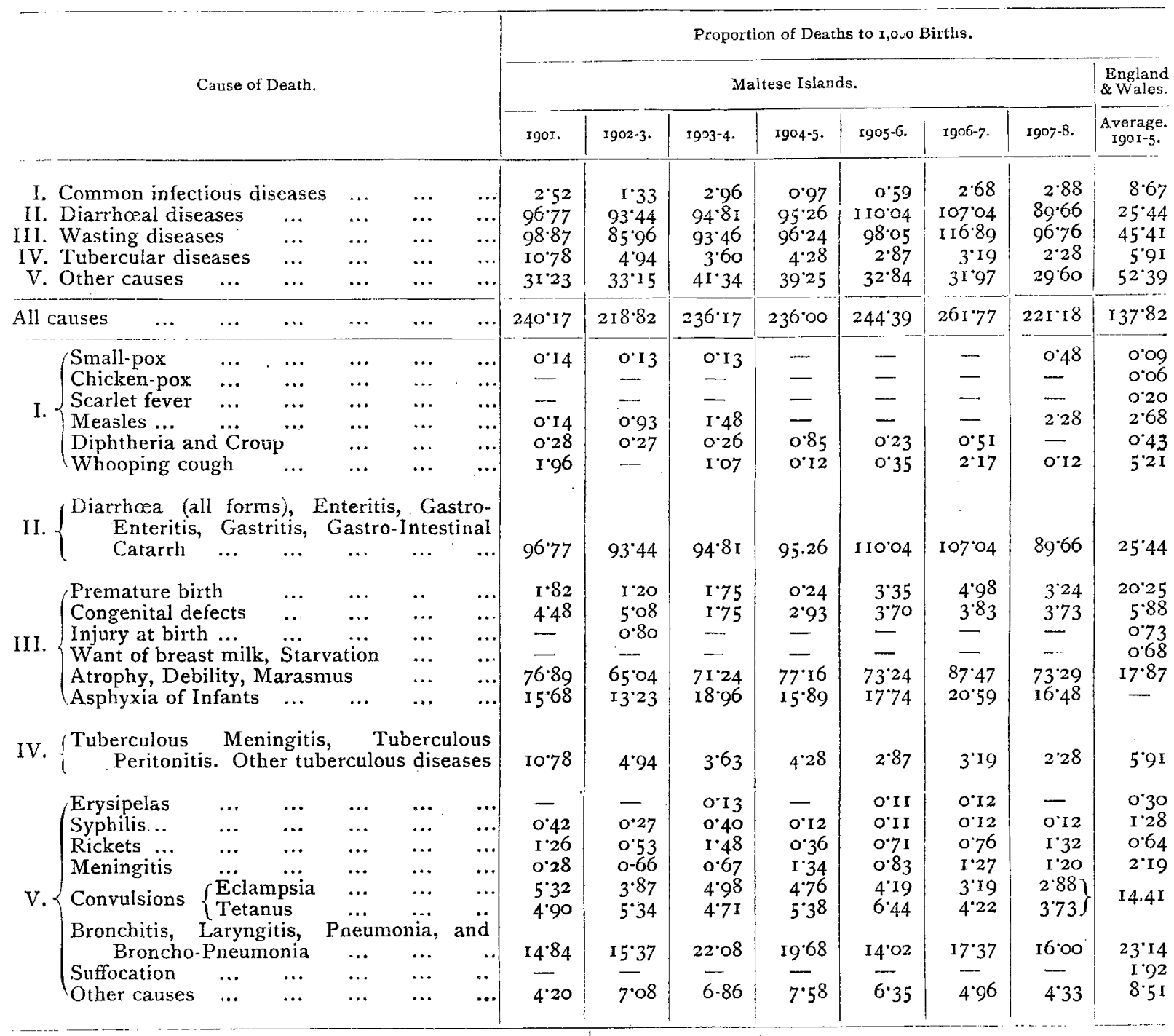

2 I per cent. of the deaths recorded during the last three outbreaks - I897-8, I903-4 and I907-8-having occurred amongst infants of that age.

Diphtheria must have made its appearance in Malta in or about 1857 as part of a general prevalence over the whole of Europe. It is recorded that an epidemic of malignant sore throat destroyed many lives here towards the middle of the 15th century. Whether this disease was the true angina diphterica and whether other outbreaks occurred since then I am unable to say.

In I859-6o-6I we find croup causing 95 deaths; in the first two quarters of 1865 croup and quinsy were responsible for 77 deaths. There is little doubt that the majority of these deaths were due to different localizations of the Klebs-Loeffler bacillus, but the name Diphtheria does not appear in official records before 1872 .

Diphtheria is now endemic in these islands.

Diphtheria, a toxic disease par excellence, requires a force of resistance rarely to be found in very young children; its mortality at the age under consideration, is, therefore, very high; but as the incidence of the disease is greatest upon children of older age, its importance as a contributor to our high infant death rate is comparatively small. Of 492 
deaths during the period $1896-$ I907-8 only 4.5 per cent. were of children under one year.

Amongst the diseases in Group I, whoopingcough is exceptionally fatal to infants; of all the deaths for the last twelve years, in fact, 537 per cent. occurred in the first year of life. This compares unfavourably with the proportion-40 per cent.- - set down by Parkes and Kenwood, presumably for England. And yet, like measles, whooping cough is not regarded by the public with anything like seriousness.

As in the case of measles, an outbreak of whooping cough is generally attended with a rise in the number of deaths due to pulmonary diseases, capillary bronchitis or bronchopneumonia being the most common fatal complication.

The disease is endemic. Sporadic cases are never absent, which, whenever fresh susceptible children are found, give rise to epidemics limited more or less to one or other part of the island.

Sometimes the disease assumes a more general character, but its spread is remarkably slow. The season does not appear to have much influence on these epidemics ; if anything, they seem to be more prevalent during the winter and spring.

Diarrheal Diseases.-Our death rate for diarrhœeal diseases under one year is enormous.

While a saving of life is being effected at ages above one, the incidence and mortality under one show no sign of improvement.

Whatever may be the clinical features of these more or less acute affections of the gastro-intestinal tract in infants, they are true intoxications caused by abnormal fermentations due to one or more species of bacteria ingested with food, or having the intestine as their normal habitat.

The circumstances bearing upon the incidence and mortality of zymotic gastro-enteritis in these islands are mainly connected with the (a) atmospheric temperature, (b) feeding of infants, $(c)$ disposal of sewage and scavenging, (d) want of cleanlinesss among the poor section of the population.

(a) Atmospheric Temperature. - The records for the last ten years indicate that the mortality curve begins to increase towards the middle of April, when the atmospheric temperature has attained about $60^{\circ} \mathrm{F}$. In June, when the mean temperature is at or a little above $70^{\circ} \mathrm{F}$., the deaths suddenly shoot up to a figure more than double that returned for
May. The maximum mortality is reached in July (mean temperature $75^{\circ}-8 \mathrm{I}^{\circ} \mathrm{F}$.). It keeps very high in August; from this month it slowly falls to a minimum in February.

Whatever the relation of diarrhœa mortality to the mean temperature of the $4 \mathrm{ft}$. soil thermometer may be, the records for Malta show that it is undoubtedly affected by the atmospheric temperature.

(b) FEeDing.-In Malta almost every mother nurses her own baby. Infants, therefore, should stand the best chance against diarrhœal and all other diseases, were it not for the fact that the mother's milk is supplemented with fresh or tinned milks, patent foods, biscuits, bread, soups, cooked flour, etc., whatever the age of the baby and whether it requires it or not. All the beneficial effects of breast feeding are thus destroyed by overfeeding and by the administration of the most improper food, either by hand or by the bottle. It is ignorance and mistaken kindness on the part of the mothers, combined with a strict adherence to habits handed down to them by previous generations, that are responsible for the appalling mortality under this heading. Indeed, credit must be given to the Maltese mother for being exceedingly fond of her offspring and for submitting herself most cheerfully to the burdens of motherhood.

(c) Sewage Disposal and Scavenging.On the speedy removal of all excreta and refuse, so that the air, water and soil shall not become polluted, depends to a great extent the healthiness of inhabited centres. These circumstances have a very direct influence on the prevalence of, and mortality from, diarrhœal diseases.

Up to a few years ago, only the towns properly so called and one of the suburbs were provided with a water carriage system of sewerage. They are still the only populated centres that have most of their streets and footways imperviously paved and flagged. Sewerage works in the other suburbs were not completed before Ig05; since then some of the villages have been taken in hand. All the conditions bearing most unfavourably on diarrhoea incidence and death rate are, therefore, still to be found in the rural districts: streets and backyards not paved imperviously, soft stone floorings in houses, cesspools, dung and ash-heaps inside or close to the dwellings, stabling and penning of animals in ground floors and cellars, discharge of slops and refuse into the streets. It is thus that the surroundings of houses-the porous roadways and yards and 
the dust-laden air-are necessarily contaminated with the various micro-organisms which are the causal agents of epidemic diarrhœa.

In the following table the diarrhoa deathrate under one for the towns and for a representative group of the country populated centres are given :-

Diarrhcea Death Rates Under One Year PER I,OOO BIRTHS.

\begin{tabular}{|c|c|c|c|c|c|}
\hline Locality. & $\begin{array}{c}\text { Total } \\
\text { population } \\
\text { xgor. }\end{array}$ & I90I. & Ig02:-3. & 1903-4 & I904-5. \\
\hline $\begin{array}{l}\text { Towns- } \\
\text { Valetta ... } \\
\text { Senglea ... } \\
\text { Cospicua ... } \\
\text { Vittoriosa } \\
\text { Populated centres in } \\
\text { the country- } \\
\text { Birchircara, Curmi, } \\
\text { Lia, Balzan, Attard, } \\
\text { Musta, Naxaro, Mel- } \\
\text { lieha, Zebbug, Zur- } \\
\text { rico, Micabiba,Axiak, } \\
\text { Luca, Zabbar }\end{array}$ & 53,017 & 102 & 96 & 120 & $12 \mathrm{I}$ \\
\hline
\end{tabular}

The difference is very appreciable. It is due mainly to the contrast in the sanitary circumstances already referred to, and to another factor, the domestic fly-the importance of which in commenting upon the diarrhoa mortality of these Islands cannot be overestimated.

The diarrhoa season is the fly season.

The methods of sewage and refuse disposal as practised in the rural districts, and the climatic conditions special to these islands are most favourable to the early and extended breeding of flies. In the villages they breed in swarms. Their rôle as disease carriers from the diarrhoeal excreta lying on the roadway, from the soiled clothes or the dung heap in the yard of the next-door dwelling, to the baby's food or to its very mouth, is as easy as it is unhindered.

(d) Cleanliness. - The germs of the disease are introduced into the alimentary canal with food, liquid or solid, specifically contaminated, or by the sucking of dirty objects, dirty teats, fingers, comforters and clothes. There is no other disease against which cleanliness intelligently and unremittingly applied would prove a more effective barrier than summer diarrhœa. Domestic cleanliness as observed amongst the poor section of the population is in Malta, as in most other countries, still rudimentary; its efficacy as a preventive of diarrhoal diseases has not as yet been understood.
Wasting Diseases.-Congenital debility is the largest contributor to the very heavy yearly death toll exacted by the diseases in this group. Although to a certain extent "debility" is the realm of the undefined and the undiagnosed, there are causes at work all through the period of gestation which, while permitting the child to be born alive, considerably jeopardise its chance of survival.

Alcoholism, syphilis, and factory work have not as yet made themselves much felt in the production of weaklings. The most operative cause in this respect is frequent childbearing where the struggle for life is hardest. Confinements follow one another so closely that the mother has no time to repair the great strain every child must make on her whole organism before and during birth. This together with injudicious and wasteful suckling, malnutrition, overcrowding and unmindfulness of the first laws of health, is responsible to a great extent for the production of the congenitally weak that contribute so effectively to raise our infant death rate.

Although asphyxia of infants is more intimately connected with the various complications of full term labour than with prematurity, the large mortality rate for the latter in the returns for England and Wales suggests the probability that it includes also the deaths from "asphyxia," which in the local returns are shown separately.

Tubercular Diseases.-It is not safe to draw any conclusion as to the prevalence of tubercle among the infant population of these islands from the tabulated death rates.

The predominant certified cause of death is tuberculosis of the mesenteric glands, or tabes mesenterica. Tubercular peritonitis, enteritis, meningitis and generalised tuberculosis represent a very small minority. If due consideration be given to the fact that goats' milk, almost the only kind of fresh milk used in Malta, has very rarely, if ever, been found to contain the specific bacillus, one would expect the mortality rates to be smaller.

The sudden drop in the figures for $1902-3^{*}$ may, in part, be accounted for by the separation of "leucocythremia " from "tubercle" in the tabulation of diseases causing death. A corresponding rise is observed under deaths from "other causes." There is little doubt that a better designation of disease and better diagnosis are helping to gradually lessen our

* The average death rate for all forms of tubercle for the period $r 602-2$ to $1907-8$ is $1{ }^{\prime} 429$ per $I, 000$ persons. 
tubercle death rate, so that it may represent the true proportion of infant life lost through this disease.

In the case of tabes mesenterica especially, the accepted symptomatology represents, in the words of Marfan, un tableau de fantaisie. Most of the symptoms, whether physical, functional or general, are not pathognomonic; the others are not very easy of determination. It is likely, therefore, that many deaths are being justly referred to chronic gasto-intestinal catarrh, a disease incomparably more common at the age under consideration.

OTHER CAUSES. - With the exception of rickets, all the diseases in Group $V$. show a substantial asset in our favour. This is more gratifying as the group includes "convulsions" and "diseases of the respiratory tract," both very common amongst infants.

With reference to our tetanus mortality, it must be said that, if the same pathogenesis be admitted to hold good for the disease as observed at ages over and under one, a more enlightened application of asepsis and a proper knowledge of the etiology of the disease on the part of midwives ought to render tetanus neonatorum a very rare accident. It is true that the disease is appreciably less frequent in cold climates, but our tetanus death rates are much higher, when compared with those of England and Wales," than the mere influence of climate should account for.

Underlying the etiology of nearly all the diseases causing death in infants are two conditions which, in my opinion, should not be lost sight of in accounting for our excessive infant mortality. I refer to the high birth rate and to the great density of population in these islands.

During the last twelve years the birth rate has never been lower than 36 and has even gone so far as $4 \mathrm{I}$ per I, ooo. In this age of vanishing birth rates these are admittedly high. They are due to exceptional fertility and early marriages. From the last two census returns, in fact, it appears that out of every thousand women of ages $\times 5-20$, seventy-nine had contracted marriages in $189 \mathrm{I}$ and sixty-four in $\mathrm{I} 9 \mathrm{O} \mathrm{I}$. Similarly, the number of children born to every thousand married women of ages I5-45 was three hundred and thirty-six in $\mathrm{I} 8 \mathrm{~g} \mathrm{I}$, and three hundred and forty-three in Igor.

The density of the population (census IgoI), were the inhabitants evenly distributed over

\footnotetext{
* England and Wales.-Tetanus.-Deaths of children under one year to 1,600 births: $1904,0.08 ; 1405,0.07 ; 1900,008$.
}

the whole area of these islands - I 7,36 I square miles-would be represented by I,67I persons to the square mile. In the least crowded village and town it would be expressed by 19,877 and Io6,894 respectively. All these figures are exceptionally high, and are the result of overcrowding on space as well as in dwellings.

These conditions, on account of their intensity, are peculiar to Malta.

Whilst overcrowding promotes diarrhœal mortality, exuberant natality is intimately connected with a high debility death rate; and it is due to the enormous loss of life from diarrhoea and debility that our infant mortality compares so unfavourably with that of other countries.

The Causes of Infant Mortality.-More than half the deaths occurring during the first year of life are practically, so far as the infants themselves are concerned, non-preventible, and are due to sociological causes, such as the marriage of the unfit; the inability to obtain sufficient food in a certain section of the community; the squandering of potential vitality on alcohol; the vitiated taste for stimulating rather than nutritious foods; the consumption of patent medicines, which, frequently taken, lower the vitality, and at times are used undoubtedly for ulterior purposes, and which, while not acting as desired, result in the production of weaklings; and the indifference of the community in general to the science of Eugenics.-Anmual Report of Dr. F. Huntun, Medical Officer of Health, Sedgefield Ruval District.

The Sanitary Control of Nomadic Gipsies. -Considerable trouble was given during I908 by bands of nomadic gipsies who encamped on lands in a part of Mortlake, adjoining Richmond. Police court proceedings were instituted in many cases against gipsies whose names could be obtained, for contravention of the bye-laws respecting water supply to dwellings. But, almost always, before the summonses could be served the camp was struck, or if the summonses were served, a move was made before the hearing came on. As a matter of fact, objectionable as the presence of these nomads no doubt is to dwellers in the vicinity of the encampments, no nuisance in a sanitary sense is caused by them in this district as a rule. It was suggested that the proper means of dealing with the annoyance was for the owners of the property to fence in their lands, and after correspondence, this was decided on by them. Bye-laws specifically dealing with these encampments might perhaps be framed, for application to urban districts.-Ammal Report of Dr. Crookshank, Medical Offer of Health, Barnes. 